\title{
Successful Treatment of Diffuse Normolipemic Plane Xanthoma with Probucol
}

\author{
Fumi Miyagawa Takaya Fukumoto Nobuhiko Kobayashi Hideo Asada \\ Department of Dermatology, Nara Medical University, Kashihara, Japan
}

\section{Key Words}

Plane xanthoma $\cdot$ Normolipemic $\cdot$ Probucol

\begin{abstract}
We report on a 70-year-old woman with diffuse normolipemic plane xanthoma (DNPX) who developed macular yellowish patches on the eyelids, both cheeks, and the nose. Histology revealed the accumulation of CD68-positive foam cells and Touton giant cells in the superficial dermis. Plasma lipid levels were within normal limits. The patient had no underlying hematological diseases. Her extensive lesions precluded surgical excision. The patient was given oral probucol instead, which resulted in a significant reduction of the lesions after 2 weeks. The lesions almost disappeared within 8 months. Plane xanthoma is primarily treated with excisional or abrasive therapies; however, probucol can be a safe and effective alternative therapy for DNPX.
\end{abstract}

\section{Introduction}

Diffuse normolipemic plane xanthoma (DNPX) was first described by Altman and Winkelmann in 1962 [1]. The features of this entity are: (1) xanthelasma palpebrarum; (2) diffuse xanthoma planum of the head, neck, trunk, and extremities, and (3) plasma lipid values that are within normal limits. Several associations have been reported between DNPX and lymphoproliferative and myeloproliferative disorders, particularly multiple myeloma and benign monoclonal gammopathy (often $\operatorname{IgA}$ ) $[2,3]$. All therapeutic options for the treatment of plane xanthoma include mechanical removal by excision, chemabrasion, dermabrasion, or abrasive laser therapy [4-6]. We report on a patient with DNPX who received oral probucol and showed significant clearing of the lesions. We suggest that probucol be included as a primary therapy for DNPX. 


\section{Case Report}

A 70-year-old woman presented with well-defined macular yellowish patches on her eyelids, both cheeks, and the nose lasting over a few years (fig. 1). She had no history of topical steroid use or extensive sun exposure on her face. Her medical history was unremarkable. A skin biopsy specimen revealed the accumulation of foam cells and Touton giant cells in the superficial dermis (fig. 2). These cells were CD68 positive, and CD1a and S-100 negative. Complete blood count, and liver and renal function tests were within normal limits, but she had elevated levels of IgA [460.7 mg/dl (normal values: $100-400 \mathrm{mg} / \mathrm{dl}$ )] and amylase [270 IU/l (normal values: 40-120 IU/l)]. No M protein was noted. Plasma lipid levels including total cholesterol, HDL and LDL cholesterols, triglycerides, and apolipoproteins were normal. Chest X-ray and abdominal ultrasonography were also normal. She was diagnosed with idiopathic macroamylasemia and treatment was considered unnecessary. Based on the clinical and histopathological findings, a diagnosis of DNPX was made and oral administration of probucol (500 mg/day) was initiated. The lesions began to recede after 2 weeks and had almost resolved within 8 months (fig. 3).

\section{Discussion}

DNPX, first described in 1962 [1], is characterized by diffuse, yellow to orange, slightly elevated plaques with sharply delineated borders that may affect any part of the body. Normolipemic cutaneous xanthoma can be categorized into 3 groups: type I-III. Type I contains patients with xanthomas found in association with an altered lipoprotein content or structure. Type II is associated with an underlying lymphoproliferative disease. Type III consists of patients with neither lipoprotein abnormalities nor underlying systemic disease, but in whom local tissue alterations seem to play a role in xanthoma formation [7].

Several therapeutic options exist for the treatment of plane xanthoma. Lesions can be removed by excision, chemabrasion, dermabrasion, or abrasive laser therapy [4-6]. Lorenz et al. [4] used an Er:YAG laser for full-face DNPX lesions under general anesthesia and reported that the lesions were almost completely removed after 2 sessions. Although these excisional or abrasive therapies may be useful for limited lesions including palpebral xanthelasmas, they may be too invasive for widespread lesions. In addition, a risk of scarring has been associated with these treatments. Therefore, another therapeutic option with medication may be warranted.

Probucol is an antioxidant that may inhibit atherogenesis by limiting the oxidative modification of LDL cholesterol [8,9] and, thus, foam cell formation and/or endothelial cell injury [9]. It has been used for the treatment of hypercholesterolemia in some countries including Japan [8]. Harris et al. [10] showed that xanthelasma lesions decreased in size in their 7 cases, and 3 lesions disappeared during probucol therapy in patients with hypercholesterolemia. Furthermore, 17 out of 25 xanthelasma patients (68\%) with normolipemia exhibited regression after taking probucol [11]. Therefore, we used probucol to treat our patient with DNPX. The results obtained were remarkable, and we suggest that probucol be included as a primary therapy for DNPX. 
Miyagawa et al.: Successful Treatment of Diffuse Normolipemic Plane Xanthoma with Probucol

\section{References}

1 Altman J, Winkelmann RK: Diffuse normolipemic plane xanthoma. Arch Dermatol 1962;85:115-122.

2 Lynch PJ, Winkelmann RK: Generalized plane xanthoma and systemic disease. Arch Dermatol 1966;93:639646.

3 Marcoval J, Moreno A, Bordas X, Gallardo F, Peyri J: Diffuse plane xanthoma: clinicopathologic study of 8 cases. J Am Acad Dermatol 1998;39:439-442.

-4 Lorenz S, Hohenleutner S, Hohenleutner U, Landthaler M: Treatment of diffuse plane xanthoma of the face with the Erbium:YAG laser. Arch Dermatol 2001;137:1413-1415.

-5 Fulton JE: Dermabrasion, chemabrasion and laser abrasion. Dermatol Surg 1996;22:619-628.

-6 Carpo BG, Grevelink SV, Brady S, Gellis S, Grevelink JM: Treatment of cutaneous lesions of xanthoma disseminatum with $\mathrm{CO}_{2}$ laser. Dermatol Surg 1999;25:751-754.

7 Parker F: Normocholesterolemic xanthomatosis. Arch Dermatol 1986;122:1253-1257.

8 Yamamoto A: A unique antilipidemic drug - probucol. J Atheroscler Thromb 2008;15:304-305.

-9 Parthasarathy S, Young SG, Witztum JL, Pittman RC, Steinberg D: Probucol inhibits oxidative modification of low density lipoprotein. J Clin Invest 1986;77:641-644.

-10 Harris RS, Gilmore HR, Bricker LA, Kiem IM, Rubin E: Long-term oral administration of probucol [4, 4'(isopropylidenedithio) bis(2, 6-di-t-butylphenol)] (DH-581) in the management of hypercholesterolemia. J Am Geriatr Soc 1974;22:167-175.

11 The Probucol Clinical Research Group: Effects of probucol on xanthoma regression (in Japanese). Nishinihon J Dermatol 1990;52:1230-1238.

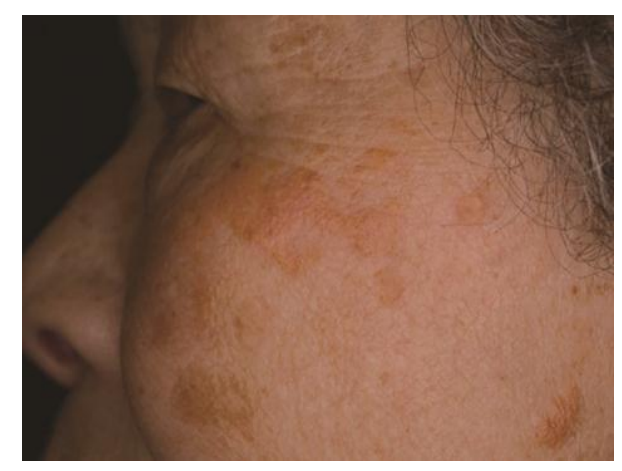

Fig. 1. Yellowish slightly elevated plaques on the patient's left cheek.

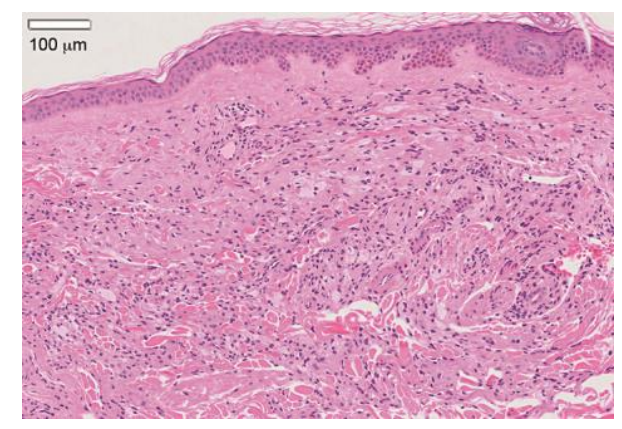

Fig. 2. Clusters of foam cells and Touton giant cells were seen in the superficial dermis (HE staining). 


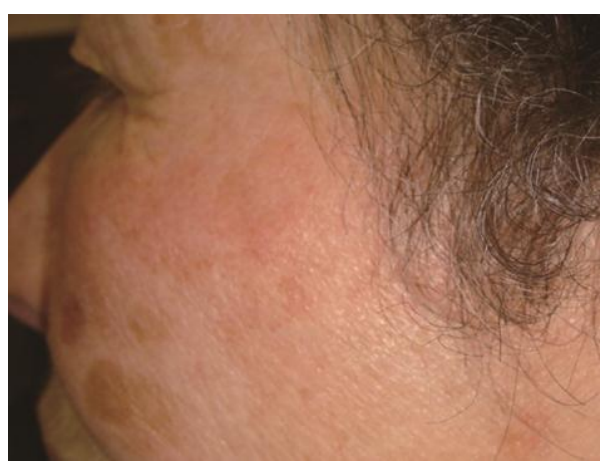

Fig. 3. After 8 months of therapy, the lesions had virtually disappeared. 